\title{
Grabstelle von Prof. Dr. Walter Friedrich wiederentdeckt und hergerichtet
}

Noch rechtzeitig vor seinem 129 . Geburtstag am 25.12.12 befindet sich die Grabstelle von Prof. Dr. Walter Friedrich wieder in einem würdigen Zustand.

Im Laufe der letzten Jahrzehnte seit seinem Ableben am 16.10.1968 war das Wissen über den Bestattungsort leider verloren gegangen, zumal auch keine Verwandtschaft mehr ermittelt werden konnte. Hinweise alter Berufskollegen Friedrichs, die bei seiner Bestattung anwesend waren, gaben erste Anhaltspunkte welcher Fried- hof infrage kommt. Als dieser Berliner Friedhof dann recherchiert werden konnte, war das Grab aufgrund der Überwucherungen zunächst unauffindbar.

Der Verein „Grabstättenerhaltung Berlin e. V." nahm sich der Sache an und gemeinsam mit der Deutschen Röntgengesellschaft konnte die Säuberung des Grabes veranlasst werden.

Weitere Informationen finden Sie auf www.berlin.friedparks.de.

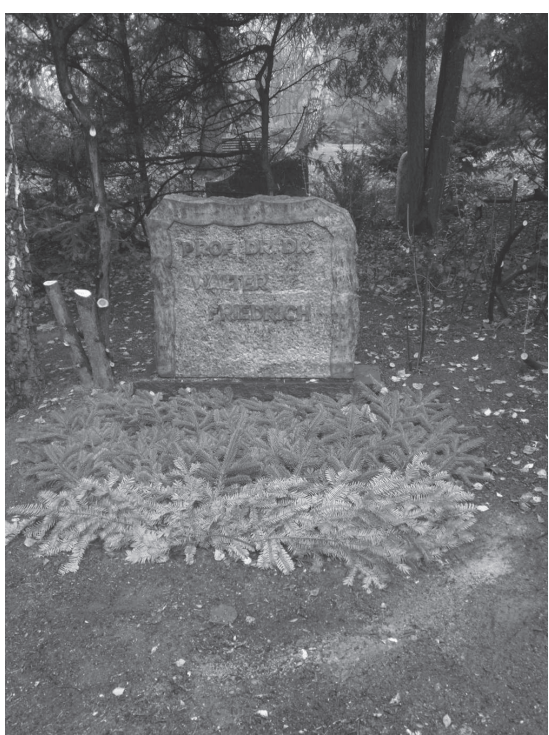

